\title{
Iconografía, estereotipos y manipulación fotográfica de la belleza femenina
}

\author{
M-Mar MARTÍNEZ-OÑA \\ mariamarona@ugr.es \\ Universidad de Granada \\ Ana M. MuÑoz-MuÑOZ
anamaria@ugr.es
Universidad de Granada
}

Instituto Universitario de Investigación de Estudios de las Mujeres y de Género

Recibido: 3 de abril de 2014

Aceptado: 7 de octubre de 2014

\section{Resumen}

Se estudian las tendencias en investigación que se han desarrollado en relación con la iconografía, estereotipos y el concepto de belleza femenina. El objetivo es proponer una mirada unificadora sobre la imagen de las mujeres, su iconografía, estereotipos y belleza. Temas que se interrelacionan a través de una misma dicotomía positiva y negativa, presente en la representación de las mujeres a lo largo de la Historia. Actualmente reflejada en el mercado publicitario con la imagen de la mujer ama de casa en contraposición con la mujer objeto de deseo, vida privada y pública. Para ello, se revisa la bibliografía más reciente publicada en torno a estos tres temas.

Palabras clave: Estereotipos de género, Iconografía, Manipulación publicitaria, Fotografía publicitaria, Imagen femenina.

\section{Iconography, Stereotypes and Photographic Manipulation of Female Beauty}

\begin{abstract}
Research tendencies that have been developed with regard to iconography, stereotypes and the concept of female beauty are studied. The aim is to suggest a unified view about the image of women, their iconography, stereotypes and beauty. Topics that are interrelated through the same positive and negative dichotomy, present in women's illustration throughout history. Nowadays it is reflected in the advertising market with the image of the woman as a housewife in comparison to the woman as a desire object, private and public life. In order to do so, the most recent bibliography about these three topics is gone through.
\end{abstract}

Keywords: Genre stereotypes, Iconography, Advertising manipulation, Advertising photograph, Female image.

\section{Referencia normalizada}

MARTÍNEZ-OÑA, M-Mar y MUÑOZ MUÑOZ, Ana M. (2015): "Iconografía, estereotipos y manipulación fotográfica de la belleza femenina". Estudios sobre el Mensaje Periodístico. Vol. 21, Núm. 1 (enero-junio), págs.: 369-384. Madrid, Servicio de Publicaciones de la Universidad Complutense.

Sumario: 1. Introducción. 2. Iconografía y estereotipos femeninos. 3. La manipulación de la belleza femenina. 4. Conclusiones. 5. Referencias Bibliográficas.

\section{Introducción}

Las imágenes siempre han corrido paralelas al arte, con gran diversidad iconográfica (Ortiz Gaitán, 1998). Esta diversidad permite identificar desde una perspectiva de género diferentes iconografías femeninas que han sido heredadas a través de la Historia del Arte y actualmente se encuentran reflejadas en el diseño gráfico y editorial, pu- 
diendo catalogar estereotipos femeninos junto con su evolución dentro de un ámbito donde la mujer ha sido y es una eterna musa construida tras una mirada masculina. Esta eterna mirada androcéntrica perpetua modelos sociales femeninos que reproduce estereotipos tradicionales sobre la sexualidad femenina concluyendo con la representación de la mujer vinculada al ámbito doméstico y representada como objeto de deseo (Feliu Albaldejo, \& Fernández Poyatos, 2010). Estos dos roles femeninos van a ser una constante referencia en la clasificación de los estereotipos femeninos en nuestra sociedad.

La evolución de las nuevas tecnologías está íntimamente relacionada con la trasformación o des-transformación del canon de belleza femenino, ya que el concepto de belleza es retocado constantemente a través de la manipulación digital de la imagen. Es vox populi que las imágenes femeninas que se publican dentro del ámbito gráfico y editorial están retocadas, pero su cotidianidad lo ha convertido en algo normal, aceptado por todos y todas, lo que favorece la creación de una nueva conciencia estética donde se expande un canon de belleza femenino basado en imágenes irreales que aparecen en nuestro entorno, convirtiendo lo imposible en un ideal estético inalcanzable para las mujeres ya que dichas imágenes que nos bombardean constantemente están manipuladas. Mostrando a las mujeres sin líneas de expresión en su rostro, con piel de porcelana, la celulitis consigue desaparecer, blanqueo de ojos y dientes, etc.; en definitiva, perfección extrema, que favorece una estética que se asemeja más a la muñeca Barbie siliconada que a mujeres reales. La influencia de la muñeca Barbie, que se ha establecido en nuestra sociedad como un icono plástico llegando a ser un modelo fundamental de la belleza de occidente, además de una herramienta de aprendizaje para las niñas, ya que con ella practican determinados roles sociales de madre, esposa o compañera sexual (Maluenda Toledo, 2010). Dicha muñeca se creó bajo la inspiración de un comic alemán protagonizado por Lili, mujer rubia que se ganaba la vida teniendo sexo con hombres adinerados. Este personaje se convirtió en muñeca con unas medidas irreales 100-45-80, y una altura de 1.80 metros y un peso de 49 kilos, medidas antinaturales, que han creado un patrón de belleza ilusorio (Prüssing, \& Salazar, 2009). Aunque no sería correcto definir un sólo canon de belleza femenino centrado en dicha muñeca, ya que dependiendo de la publicación final de las imágenes las modificaciones van a ser distintas existiendo diferentes cánones de belleza femeninos, aunque todos retocados y manipulados. Lo que fomenta la interminable búsqueda del ideal de belleza favoreciendo la aparición de determinadas consecuencias negativas, donde posiblemente la peor es la discriminación social y profesional que a su vez conlleva a otra serie de consecuencias negativas. Ya en 1996, José Luis León Sáez de Ibarra utilizó la denominación selección socio-estética de la especie para determinar la discriminación profesional de las personas que no alcanzarán el canon estético impuesto por la publicidad.

El presente artículo pretende examinar la bibliografía más reciente publicada en torno a tres temas, iconografía, estereotipos y el concepto de belleza femenina, el cual se modifica a través de diversos programas de retoque fotográfico. Una vez recopilada, analizada y comparada dicha información en los diferentes campos de los estudios aquí planteados, se muestran diversas tendencias de las investigaciones sobre ellos. 
Siendo el objetivo principal de este articulo proponer una mirada unificadora sobre la imagen de la mujer, su iconografía, estereotipos y belleza femenina. Imágenes que hemos heredado de nuestra rica cultura y permanece instalada en nuestra sociedad por la tradición, manifestándose constantemente a través de la publicidad.

Para su recopilación se ha realizado diversas búsquedas en los catálogos de biblioteca y las bases de datos más importantes a nivel internacional (Web of Science, Scopus, Arts \& Humanities Full Text - ProQuest, ISOC on-line), de aquellos artículos más actuales que aporten una base a esta investigación con el fin de compactar las tres temáticas diferentes de este estudio. Una búsqueda más selectiva clasificó aquella bibliografía escrita desde una perspectiva de género.

\section{Iconografía y estereotipos femeninos}

El estudio de la iconografía femenina permite identificar e interpretar diversos temas mostrados de forma reiterada en las imágenes que se publican dentro del diseño gráfico y editorial, y por su extensión también en publicidad; se trata de iconos heredados a través de la Historia del Arte que siguen vigentes en la iconografía femenina actual.

Actualmente se muestra un gran interés por estudiar dicha iconografía desde una perspectiva de género (Diego Otero, 1987, 1992; Bornay, 1990, 1994, 1998, 2009; Castañer López, 1993; Ulierte Vázquez, 1997, 1998; Sauret Guerrero, 2007; Aumente Rivas, 2010). Estos trabajos defienden la existencia iconográfica de una dicotomía femenina, el Bien y el Mal representado iconográficamente por el ejemplo a seguir y a detestar, relacionado con la imagen de María y Eva o Lilith en la cultura occidental, la racionalidad frente a los sentimientos, el mundo privado frente al público, etc. Destaca también una construcción dicotómica del modelo femenino mediático madre-esposa versus vampiresa-sensual devoradora (Moya Richard, 2010). Convirtiéndose así en un tema muy atractivo el estudio de la iconografía de mujeres malvadas, a través de ellas numerosas culturas han asociado el concepto de femineidad al mal (Gache, 2012). La mujer-arquetipo como expresión del inconsciente colectivo dentro del mundo del psicoanálisis estudiado por Jung, ejemplificando diversas iconografías-arquetipos femeninos apoyados en diferentes ejemplos visuales (Saiz Galdós, Fernández Ruiz, \& Álvaro Estramiana, 2007). Los estudios iconográficos femeninos también se realizan en Latinoamérica donde se estudia la imagen femenina en la prensa mexicana (Ortiz Gaitán, 1998, 2003). En publicidad también se pone de manifiesto dicha iconografía identificando la dicotomía entre la racionalidad/cultura/mente/espacios públicos representado por el hombre frente a la irracionalidad/naturaleza/cuerpo/espacios privados representado por la mujer (López Pérez, 2009), o estableciendo una dicotomía mujer/hombre que relaciona con intuición/intelecto, irracionalidad/racionalidad, objeto/sujeto, etc. (Maluenda Toledo, 2010).

Erika Bornay (1990) en relación con la iconografía femenina afirma en su libro Las Hijas de Lilit la existencia de diferencias entre hombres y mujeres, pero dicha diversidad no implica inferioridad ni superioridad, ni justifica la repetición de modelos erróneos que favorecen a unos y sacrifican a otros. La iconografía femenina manifiesta un canon de belleza femenino que ha sido creado por el ámbito masculino, im- 
poniéndose éste al femenino creando repercusiones negativas que esclavizan el aspecto físico de las mujeres, ya que se trata de un canon inalcanzable e irreal. Partiendo de esta idea Nuria Rodríguez Díaz (2012) plantea hasta qué punto las mujeres son musas o no, ya que a partir de una visión masculina de ver el mundo, la mujer se ha convertido en un objeto de la mirada, un fetiche de belleza, un objeto de contemplación, convirtiéndose su cuerpo en el punto más importante para ser mirado. Así, el cuerpo femenino queda sometido a paradigmas estéticos masculinos, Carmen Arocena Badillos y Nekame Zubiaur Gorozika (2012) consideran que en este imaginario simbólico femenino, construido y extendido por los medios de comunicación de masas, es en sí mismo una forma tácita de violencia (no siempre) sobre la mujer.

Vivimos en una sociedad tremendamente visual donde constantemente percibimos imágenes a través de los medios de comunicación, dichas imágenes son aceptadas como reales ya que están instaladas en nuestro imaginario, sin plantearnos ninguna duda, quizás por la costumbre de haberlas estado viendo a lo largo de nuestras vidas. Es necesario releerlas para identificar los iconos que nos permiten reconocer iconográficamente la imagen, así determinar la veracidad de lo que vemos. Ya que si todo se acepta, si replantearnos lo que percibimos estaremos condenado la imagen no solamente del cuerpo femenino, sino de lo femenino y con ello sometiendo a todas las mujeres a representar un rol creado desde una perspectiva androcéntrica.

No hay que olvidar que «el Arte» fue creado por y para el deleite masculino, este hecho -justificado en la búsqueda de la belleza- ha impuesto e impone un canon de belleza que la mujeres no eligen, creando una iconografía femenina bajo una perspectiva masculina, que ha sido base de nuestra historia, de nuestra educación y cultura. Junto con los diferentes iconos femeninos se crean diversos estereotipos de belleza que a lo largo del tiempo han ido cambiando. Las imágenes artísticas y publicitarias transmiten determinada ideología, influyendo en la construcción de identidades, lo que concluiría en una sociedad patriarcal excluyente donde las mujeres asumen un papel subordinado y las ideas estereotipadas ponen freno a una sociedad igualitaria, como ocurre con la representación del cuerpo femenino desde la perspectiva androcéntrica, la publicidad hereda un ideal de belleza que unifica la feminidad, lo que supone el control de la identidad femenina (Diego Otero, 1987).

Iconografía y estereotipos, ¿qué son los estereotipos? ¿cómo nos afectan?. Efectivamente, la iconografía desemboca en los estereotipos femeninos los cuales se han extendido a través del arte y han sido incorporados al imaginario colectivo gracias a la publicidad, a los medios de comunicación, y cómo no, a Internet. En esta expansión iconográfica la publicidad ha desempeñado y desempeña un papel fundamental no solamente en la construcción de estereotipos o deconstrucción, como afirma Susana López Pérez (2009) quién se pregunta cómo se construye o reconstruye la realidad, ya que ésta captura significados existentes del imaginario colectivo adaptándolos a lo que publicita envueltos en valores simbólicos, siendo la publicidad un espejo deformante que reflexiona y modifica la cultura social, instalándose en nuestra cotidianidad diaria. Compartiendo esta idea de espejo deformante, Ángeles Feliu Albaladejo y $\mathrm{M}^{\mathrm{a}}$ Dolores Fernández Poyatos (2010) acusan a la publicidad y a los medios de comunicación de ser los responsables en la configuración de una visión estereotipada de 
la mujer, ofreciendo un reflejo deformado que va calando en el imaginario colectivo. No hay duda, de que La publicidad recurre a las creencias del imaginario social, los estereotipos (García Leiva, 2003).

Las primeras investigaciones sobre estereotipos de la mujer en publicidad se realizaron en Estados Unidos con Culley y Bennet en 1976, determinando éstos que las mujeres que se representan están más preocupadas por su aspecto físico y por las tareas domésticas, y raras veces aparecerían como profesionales (Garrido Lora, 2007).

Los estereotipos construyen la realidad social, atribuyendo un rasgo a todos los miembros del grupo sobre generalizando y construyendo prejuicios (López Pérez, 2009). Éstos han sido heredados y actualmente siguen vigentes como se analiza en diferentes estudios que concretan estereotipos femeninos en publicidad (García Leiva, 2003; Diaz Soloaga, \& Muñiz Muriel, 2007; Garrido Lora, 2007; Cáceres Zapatero, \& Díaz Soloaga, 2008; López Pérez, 2009; Maluenda Toledo, 2010; Moya Richard, 2010; Martínez Rodrigo, 2010; Sabelli, 2012; Soley Beltrán, 2012). Manuel Garrido Lora (2007) define, como ya lo hizo $\mathrm{M}^{\mathrm{a}}$ Luisa Balaguer en 1987, cinco tipos de mujeres en publicidad española, mujer ama de casa, mujer trabajadora, mujer belleza (objeto), mujer inferior al hombre y mujer valor asociado a un producto. Posteriormente, Cristina Peña-Marín y Carlo Frabetti (1990) identifican a un nuevo estereotipo, mujer independiente y trabajadora. José Luís León (2001) destaca siete estereotipos que relaciona con diosas grecorromanas, Artemisa-autosuficiente, Atenea-racional y emprendedora, Hestia-la sabia ancianidad, Hera-exigente, Deméter-madre, Perséfonecomplaciente y víctima, Afrodita-pasión sensual. Mientras que Susana López Pérez (2009) identifica dos estereotipos, el primero es el de ama de casa, esposa y madre, y un segundo estereotipo sería el de mujer objeto de deseo, y por extensión mujer fatal, definida como mujer dispuesta a ser conquistada por el hombre dominador, aunque su comportamiento sensual y su canon de belleza se aleja de las mujeres normales, a éste estereotipo se le añade incapacidad intelectual, siendo un icono ampliamente mostrado en campañas de perfumes y en otras destinadas al público masculino, planteando cómo el público masculino debería reflexionar sobre imagen que se ofrece de él, estableciendo un paralelismo con un animal en celo. Ambos estereotipos femeninos estarían unificados en la publicidad en un solo ser, ya que ambos se complementarían al hacer feliz al hombre como madre y ama de casa y transformándose en la vampiresa que los hombres desean (López Pérez, 2009). La publicidad usa estereotipos que comúnmente son aceptados, éstos definen cómo debe de ser una mujer o un hombre para triunfar social y afectivamente en nuestra sociedad. Dentro de las marcas de modas en España se definen cinco estereotipos femeninos, la publicidad de la moda de lujo refuerza diversos estereotipos femeninos; alimentando estereotipos sociales que ensalzan una imagen de mujer entendida como objeto, donde la espiral de lujo encierra a la mujer en un bucle de consumo cuyos valores esenciales es conseguir la belleza y juventud (Díaz Soloaga, \& Muñiz García, 2007). Mª Dolores Cáceres Zapatero y Paloma Díaz Soloaga (2008) amplían este estudio y definen cinco estereotipos femeninos, mujer tradicional que refleja amor maternidad y familia, mujer trasgresora, relacionada con triunfo, libertad, conquista, fidelidad y trasgresión. Mujer frágil o sometida relacionada con tristeza, debilidad, languidez y sometimiento, mujer hedo- 
nista-sensual, representada por la atracción sexual, seducción, y placer y mujer funcional-moderna relacionada con imágenes de modernidad, gozo y comodidad. Los medios refuerzan los estereotipos femeninos tradicionales, considerando a las mujeres como objeto sexual del consumidor, proyectando una imagen femenina de quiénes somos y de lo que se espera de nosotras. Existiendo una evolución de la imagen femenina a través de anuncios publicitarios los cuales se clasifican en diferentes épocas, años 40-50 mujer ama de casa, años 60-70 mujer que comienza a reclamar su independencia, años 80-90 mujer ejecutiva, culto al cuerpo y top-model, siglo XXI donde la publicidad busca caminos alternativos para una consumidora preocupada por el medio ambiente y alejada del concepto de top-model (Martínez Verdú, 2007). Cheryl Prüssing y Constanza Salazar (2009) concretan ocho estereotipos femenino: ama de casa, esposa y compañera, trabajadora y ama de casa, profesional, independiente, joven y moderna, símbolo de belleza, y objeto de deseo. Ana Lucía Villareal (2010) analiza, clasifica y ejemplifica diversos estereotipos femeninos que reproducen los mensajes publicitarios televisivos, diferenciando entre virgen, creadora y destructora, amante y seductora, madre, sacerdotisa y hechicera, musa. Destaca a su vez determinados cautiverios para las mujeres que clasifica en madresposa, putas, monjas, presas, locas. Ángeles Feliu Albaladejo y Ma Dolores Fernández Poyatos (2010) repasan los estereotipos de hace cuatro décadas y su evolución, destacando cómo existían tres tipos de trabajos femeninos, educación, enfermería y secretariado, contraponiendo entonces, con los nuevos estereotipos, mujer trabajadora y ama de casa, mujer dependiente y profesional, mujer profesional, mujer independiente, y mujer del siglo XXI. Patricia Soley Beltrán (2012) destaca una de los estereotipos actualmente más extendidos íntimamente relacionado con la belleza, mujer bella como sinónimo de mujer tonta, se trata de un estereotipo muy extendido entre las modelos.

Existen otras investigaciones donde se acota mucho más el estudio sobre estereotipos femeninos, como por ejemplo a través de la publicidad de las revistas ilustradas (Ramos Frendo, 2009), de la publicidad radiofónica (Fajula, Souto, \& Barbeito, 2010), de la publicidad televisa (Villareal, 2010) o en el cine de género deportivo (Ramírez Macías, et al., 2003). Se aborda el color de ojos femeninos como elemento determinante de estereotipos femeninos en los anuncios publicitarios (Martínez Rodrigo, 2010). Asimismo se han realizado estudios sobre las representaciones contemporáneas del cuerpo femenino negro y los estereotipos de éste, que confirman cómo el análisis de las representaciones pasadas y presentes del cuerpo femenino negro es una herramienta necesaria para comprender la intersección entre el sexismo y el racismo (Sabelli, 2012). Además se ha llegado a clasificar a una nueva mujer dentro de la publicidad gráfica, la mujer fálica, mujer todopoderosa que exhibe un fetiche como objeto publicitario (un helado, una botella, un frasco de perfume, etc.). Siendo entonces un cuerpo femenino dotado con un falso falo -el objeto publicitario- (Campos Rodríguez, 2008).

Dentro de los estereotipos femeninos, uno de los más conocidos es el de Lolita, que se ha representado en casi todas las Artes, literatura, pintura, fotografía, cine, etc. Los estudios de estereotipos femeninos en niñas y pre-adolescentes se centran en detectar cómo influye la industria de la belleza en la cultura mediática infantil. En relación 
con las estrellas Disney, adolescentes protagonistas de las series de Disney Channel, se muestra un modelo de mujer sexualizada que responde al prototipo de feminidad patriarcal (Verlichi Martín, 2012).

En definitiva, las imágenes que se difunden de la mujer en publicidad son estereotipadas e inexactas y negativas, donde se describe a la mujer más por su apariencia que por sus capacidades (Bernand Monferrer, 2010). Mostrando una imagen del cuerpo de la mujer construida por hombres, que enfatiza con determinado canon de belleza y juventud como valores máximos y olvida sus cualidades intelectuales, personales o sociales (Cáceres, \& Díaz, 2008). La representación mediática del cuerpo femenino es la expresión de la dominación falocéntrica al proponer un cuerpo antinatural que no envejece (Moya Richard, 2010). De manera, la publicidad convierte el cuerpo femenino en un estereotipo adaptado a las necesidades de la moda, una percha donde presentar el producto a vender (Cabrera García-Ochoa, 2010).

Cabe preguntarse si el cuerpo es un producto más necesario de vender, un elemento más de consumo donde se representan estereotipos femeninos rediseñados a lo largo de la historia, y perfectamente instalados en el imaginario colectivo. La cotidianidad fomenta que la población observemos dichos estereotipos como reflejo de nuestra cultura, incluso de nuestra vida. Es necesario aprender a releer, un nuevo modo de verlas imágenes para desmontar estereotipos cotidianos, aunque a veces como afirmaba Virginia Woolf: Es más difícil asesinar a un fantasma que a una realidad.

\section{La manipulación de la belleza femenina}

El canon clásico de belleza es un estereotipo femenino a nivel mundial expandido gracias a la publicidad, los medios de comunicación y cómo no a Internet, dicho canon discrimina a distintas razas, prevaleciendo la caucásica ignorando así, que puede haber otros tipos de belleza en el mundo. Nicolás Heredia y Gladys Espejo (2009), como cirujanos plásticos y comerciantes de la belleza, defienden que hay que identificar otros tipos de belleza para que el procedimiento quirúrgico no tenga consecuencias agresivas, abogando por la idea de una cirugía plástica natural para que los cuerpos no sufran cambios de identidad. Isabel Moya Richard (2010) pone de ejemplo como Miss Brasil 2001 necesito 24 operaciones de cirugía estética para conseguir el ansiado canon de belleza femenino. Sin duda el modelo femenino de belleza se ha construido a partir de un estereotipo occidental donde la imagen de la mujer continúa subordinada al punto de vista masculino, y su cuerpo sometido a una permanente regulación y disciplina. Se ha fabricado un cuerpo femenino perfecto durante toda nuestra historia, para ello hay que observar cómo se ha modificado la belleza femenina con durísimos aparatos correctores como corsés, fajas, etc. (Maluenda Toledo, 2010).

A lo largo de la historia el concepto de belleza ha ido ¿evolucionando o quizás transformándose? Si hiciéramos un recorrido por la historia de las ideas estéticas se puede apreciar la constate modificación del concepto de belleza dependiendo de la sociedad en la que se desarrolle dicho concepto. Ésta viene acompañada de paradigmas culturales, siendo sociedad y cultura variables dinámicas, una de estas variables es el canon de belleza femenino como refleja la Historia del Arte (Garrido, 2010). Por lo tanto, si estamos en una nueva sociedad del postcapitalismo percibimos un nuevo 
canon de belleza. Éste ha ido cambiando según el objetivo de la sociedad patriarcal (Garrido, 2010).

En el caso de las mujeres, el Arte, la publicidad y los medios de comunicación nos hacen creer que la belleza es probablemente la cualidad que nos hacen más valorable, la que se tiene en cuenta en primer lugar, la más destacable socialmente. La mujer-objeto de deseo es la que vemos en anuncios, pasarelas, concursos de belleza, juegos de ordenador, etc., proponiendo un canon de belleza imposible de alcanzar para la mayoría de las mujeres (Bernard Monferrer, 2010).

Debemos, entonces, plantearnos dos cuestiones, si ¿existe un canon o cánones de belleza determinado para las mujeres durante la primera década del siglo XXI? Y si este canon es irreal ¿Por qué se nos impone? ¿A quién le interesa fomentar una determinada estética? Para intentar responder a estas preguntas hay que mirar hacia el consumismo actual, para definir los rasgos estéticos que determinan la nueva belleza femenina del siglo XXI hay que analizar cómo el cuerpo femenino se ha convertido en un objeto más, en mercancía (Cabrera García-Ochoa, 2010; Prüssing, \& Salazar, 2009; Velásquez Fernández, 2010; Feliu Albadejo, \& Fernández Poyatos, 2010). Donde la publicidad funciona como normalizadora de cuerpos irreales para estimular un deseo no satisfecho que mueva al consumo (Moya Richard, 2010).

Lo peligroso de este modelo es no aceptar las limitaciones normales de nuestro cuerpo para vivir una felicidad viable y asequible, por el contrario nos encontramos con un ideal ilusorio y frustrante que muestra un canon inalcanzable que conduce al consumo, produce insatisfacción y merma la autoestima. Matizando que un cuerpo mercantilizado nunca será libre al estar sometido a las veleidades del mercado y a los intereses particulares (Cáceres, \& Díaz, 2008). Esta frustración femenina de la que tratan muchos autores (López Pérez, 2009; Bernand Monferrer, 2010; Cabrera GarcíaOchoa, 2010; etc.) conllevaría al desarrollo de diversas enfermedades. A su vez se genera una necesidad del mercado de generar mayores demandas en relación con el cuerpo femenino, generando un obsesivo culto al cuerpo y la necesidad de la eterna juventud, que conduce a un único modelo femenino inalcanzable para la mayoría de las mujeres, provocando obsesiones y enfermedades como anorexia y bulimia (López Pérez, 2009).

Existen investigaciones que tratan sobre el ideal inalcanzable de belleza y la salud dónde se pone de manifiesto cómo las imágenes publicitarias femeninas influyen en la autopercepción del cuerpo femenino de las adolescentes, siendo dichas imágenes femeninas irreales, el prototipo de belleza que favorece la disminución de la autoestima de las adolescentes (Crouch, \& Degelman, 1998). Otros autores han estudiado desde la psicología como los cuerpos delgados e irreales que se publican en los medios de comunicación producen diversos efectos negativos en la imagen de las jóvenes (Halliwell, $\&$ Dittmar, 2004). Afirmando que el tamaño del cuerpo de las modelos en vez de atractivo lo que genera es ansiedad entre las mujeres; a esta afirmación se unen otros autores como Yolanda Cabrera García-Ochoa (2010), Estela Bernard Monferrer (2010), Isabel Moya Richard (2010), Elena Verchili (2012), o María Victoria Carrillo (2003).

Dentro del estudio de los trastornos alimenticios se ha estudiado cómo las mujeres que presentan síntomas bulímicos reciben una mayor presión de los medios de co- 
municación para estar delgadas, defendiendo la gran influencia de los medios, que favorecen diversos trastornos alimenticios (Clay, Vignoles, \& Dittmar, 2005; Feliu Alabaldejo, \& Fernández Poyatos, 2010). Destaca los efectos negativos como la inseguridad femenina sobre su físico, lo que conlleva a un estado de ansiedad, ya que las mujeres no pueden conseguir el canon de belleza impuesto por los medios lo cual también desemboca en un descontento masculino hacia sus consortes. Generándose una obsesión por adelgazar que termina muchas veces en enfermedades como anorexia. A esto, suma la idea de la percepción fragmentada de las mujeres hace que se valoren sus características corporales en detrimento de otros valores de la persona (Martínez Rodrigo, 2010). Los medios de comunicación identifican el éxito, belleza y aceptación social con cuerpos escuálidos, lo cual induce a mujeres con problemas de seguridad o confianza, a obsesionarse por conseguir un cuerpo excesivamente flaco, siendo éste el propuesto como perfección estética (Bernard Monferrer, 2010). La existencia de la desigualdad de género entre los modelos de hombre y mujer utilizados en los anuncios donde se pone de manifiesto un desequilibrio siendo el cuerpo femenino un blanco habitual de restricción alimentaria y obsesión por la belleza, mientras los hombres muestran un entrenamiento y musculación del cuerpo lo que requiere mayor ingesta de alimentos. Quedando constatado que en el discurso publicitario difieren los cuerpos femeninos y masculinos e incluso en ocasiones son antagónicos (Cabrera García-Ochoa, 2010).

Como conclusión a estos estudios se podría recoger que la exposición de modelos delgadas en medios de comunicación tiene un efecto negativo de la imagen corporal de la mujer favoreciendo la ansiedad en mujeres adultas (Dittmar, \& Howard, 2004). Relacionada con la autoestima femenina las características corporales van en detrimento de otros valores, todo esto lleva a una clara disminución de la autoestima ya que la mujer media utiliza las imágenes idealizadas de modelos publicitarias para evaluarse a sí misma (Martínez Rodrigo, 2010).

Entonces, ¿salud o belleza? ¿qué se entiende por belleza? ¿qué rasgos físicos debe tener una mujer para ser considerada bella? ¿con que retoque conseguimos esta ansiada belleza? y ¿cómo conseguirlo a través de la manipulación fotográfica?.

Lo medios de comunicación y la publicidad han contribuido en la construcción de este nuevo canon de belleza tanto femenino como masculino. Pero habrá que tener en cuenta que no existe un manual de la publicidad que diga que para ser eficaz tenga que ser sexista, ni que deba imperar un canon de belleza femenina, sin embargo los anuncios publicitarios promocionan una imagen estereotipada, sexista, en ocasiones vejatoria sobre la mujer (López Pérez, 2009).

Las diosas inalcanzables que nos muestran las imágenes usadas en diseño gráfico y editorial, en su origen se trata de una imagen digital retocada para crear esta idealización femenina, (independientemente de posibles retoques físicos que pueda haberse realizado la modelo) que a su vez están escenificando determinadas iconografías que identifican un claro estereotipo femenino.

La manipulación de la imagen con un software informático por los medios de comunicación es estudiado por Meredith Jones (2013) quién analiza ejemplos concretos de imágenes manipuladas, poniendo de manifiesto cómo se manipulan fotografías 
para satisfacer diferentes momentos temporales y espaciales, contando así la fotografía una historia diferente que esconde la verdad cada vez que se manipula con cualquier herramienta de Photoshop, mimetizando los cuerpos en materia y proyectándolos a través de los medios de comunicación. Mostrando la seducción y los peligros de éstos a través de ejemplos concretos, donde el autor sugiere cómo se puede conseguir una comprensión más sutil de las polémicas imágenes presentadas. Intentando definir un nuevo canon de belleza informáticamente adulterado David Alandete (2011) publica un artículo explicando la existencia de un nuevo canon de belleza manipulado por Photoshop donde prima la juventud, y las mujeres no tienen arrugas, ni ojeras, ni patas de gallo, ni granos, no existe la celulitis, los michelines, o las estrías, etc. El autor también pone de manifiesto como diversos países pretenden que los anunciantes indiquen qué fotos están manipuladas informáticamente para evitar publicidad engañosa.

Iconos de belleza femeninos han sido ejemplificados a través de estrellas de cine convirtiéndose a lo largo de la historia en paradigmas de belleza, el problema de estas imágenes es que han sido alteradas a través de programas informáticos como Adobe Photoshop "que permiten arreglar los defectos naturales de las modelos" (Heredia, \& Espejo, 2009). Aunque también añaden que:

"Nos encontramos en un mundo donde la naturaleza y la tecnociencia digital se encuentran enfrentadas. Además, en la actualidad el cuerpo se encuentra enmarcado en un mundo digital, y con los diferentes procesos que se están llevando a cabo por medio de las tecnologías, el cuerpo tiende a la homogeneización, omitiendo los errores de la naturaleza." (Heredia, \& Espejo, 2009, p. 39)

Y nos podemos preguntar itener rasgos pronunciados alejados del canon de belleza actual es un error de la naturaleza? Que actualmente existan personas capaces de definir un rasgo estético como error de la naturaleza nos hace pensar en la necesidad inminente que tenemos de deconstruir el asfixiante canon de belleza femenino que nos han impuesto.

Si existen tres principios claramente diferenciados del canon de belleza actual son, juventud, belleza y delgadez. Se trata de una constante dentro del canon de belleza (Prüssing, \& Salazar, 2009; Moya Richard, 2010; Bernard Monferrer, 2010; Maluenda Toledo, 2010; Velásquez Fernández, 2010). Cheryl Prüssing y Constanza Salazar (2009) manifiestan cómo en determinadas revistas analizadas existe desprecio hacia los rasgos afroamericanos e indígenas, estandarizando los cánones estéticos de origen europeos. Jean Luc Bonniol (1995) valora los diferentes tonos de piel femeninos, prevaleciendo el blanco como ideal de belleza.

$\mathrm{M}^{\mathrm{a}}$ José Pérez Serrano, y María Romero Calmache (2010) definen el canon de belleza femenino como una figura esbelta, con medidas 90-60-90, piel tersa y bronceada, ojos grandes, nariz pequeña, boca grande y labios gruesos, senos firmes simétricos y sólidos, vientre liso, pelo largo, piernas largas, etc., y tener menos de treinta años. Susana López Pérez (2009) define dentro del estereotipo de la mujer objeto determinadas cualidades físicas como talla pequeña, labios gruesos, piernas largas, juventud, aunque destaca como la marca Dove ha apostado desde 2004 por mujeres reales. Cam- 
paña publicitaria que también comentan otras autores (Alandete, 2011; Bernard Monferrer, 2010; Cabrera García-Ochoa, 2010; Fajula, Sout, \& Barbeito, 2010; Feliu Albaladejo, \& Fernández Poyatos, 2010; Porter, 2011). María Victoria Carrillo (2003) confirma esta tendencia a la delgadez, a la vez que afirma que una mujer normal suele pesar diez kilos más que una modelo, relacionando en su estudio una similitud entre mujer triunfadora igual a mujer delgada. Siendo sinónimo de fantasía de belleza, mujer joven, blanca, delgada con poder y status, mostrándose así como deseable y alcanzable si se consumen los productos adecuados, a su vez se limita la vida útil de las mujeres modelo, la mayoría de pasarelas y anuncios raramente sobrepasa los veinticinco años, aunque existen algunas iniciativas que han pretendido mostrar a mujeres desnudas mayores de cincuenta años, también hay que destacar como hay empresas que utilizan imágenes retocadas de mujeres maduras (Soley Beltrán, 2012).

Habrá que definir, ¿hasta qué edad llega la juventud y en que retoques fotográficos concretos afecta esto? Una vez conseguido todo, preguntaremos si la publicidad, y dentro de ella el diseño gráfico y editorial construyen la realidad social actual? Realidad social, donde la belleza femenina se convierte en un producto fácilmente manipulable.

El patriarcado exhibe belleza y juventud como valores positivo, este hecho relega a la fealdad y la vejez al ámbito de lo invisible, a no formar parte de la sociedad (Arocena \& Zubiaur, 2012). La representación femenina en la publicidad tiene un efecto inmediato de idealización de la edad juvenil, tanto en piel como en silueta o en estilo de vida. Ya que en la publicidad tradicional ser mujer significa ser joven y tener un cuerpo modélico. Manipulando así no solamente nuestro físico, sino también nuestra forma de vida (Martínez Rodrigo, 2010). Dentro de la publicidad de marcas de moda de lujo el cuerpo femenino ideal es un cuerpo de piel blanca, joven y esbelto, vestido y bello, sin defectos, marcas, enfermedades o carencias. Definido por tres conceptos básicos belleza, juventud y perfección (Cáceres \& Díaz, 2008). Yudmila Irazú (2006) declara la juventud como elemento de belleza dentro de una campaña publicitaria, en México. Imagen de belleza totalmente occidentalizada (delgadas, altas, piel blanca, ojos claros y cabello largo) que nada tienen que ver con las mujeres reales mexicanas. Este ideal estético responde a éxito social, amoroso y laboral. Mientras que los estereotipos de belleza de la mujer cubana los analiza Isabel Moya Richard (2010). Los estereotipos de las mujeres chilenas, más concretamente a las mujeres de Santiago de Chile lo analizan Cheryl Prüssing y Constanza Salazar (2009). La estética en la mujer venezolana a través de dos publicaciones concretas, la expone Kasbrika Velásquez Fernández (2010) donde destaca la gran influencia en Venezuela de los certámenes de belleza, junto con los medios de comunicación.

Resumiendo, la publicidad propone mujeres bellas, con rostro y cuerpo perfecto donde no existen marcas de cansancio o de edad, o rasgos que se aparten del canon de belleza actual, afirmando que en cuatro de cada cinco anuncios se presenta un cuerpo y rostro perfecto. Lo peor de todo, es que la sociedad tiende a atribuir cualidades como el éxito social, la felicidad, etc. a las personas bellas (Cáceres Zapatero, \& Diaz Soloaga, 2008). 


\section{Conclusiones}

En torno a los temas objeto de estudio de este artículo -iconografía, estereotipos y belleza- se distinguen tres líneas de investigación, la evolución de la iconografía femenina, la identificación de diferentes estereotipos, y la existencia de un nuevo y manipulado concepto de belleza.

A través del mercado publicitario se bombardea a la sociedad actual con multitud de imágenes siendo necesario aprender a leer o releerlas, ya que su finalidad mercantil es prioritaria, pretendiendo vender no solamente una forma de vida sino una imagen determinada de mujer, para ello se apoya principalmente en una iconografía heredada, en diversos estereotipos femeninos y en un nuevo canon de belleza imposible de alcanzar ya que dichas imágenes están manipuladas por programas de retoque fotográfico, esto provoca diversas consecuencias negativas que desembocan en enfermedades como autoestima, anorexia y bulimia entre otras. La manipulación digital ha instaurado un nuevo canon de belleza femenina inalcanzable, una esclavitud silenciosa hacia las mujeres de quiénes se pretende que respondan a una belleza ideal e irreal.

Al unificar estas tres líneas de investigación, se observa en los estudios iconográficos femeninos la existencia de una dicotomía entre el Bien y el Mal, el ejemplo a seguir generalmente relacionado con la iconografía de María y la vida privada, que se contrapone con el ejemplo a detestar relacionado con Eva y la vida pública. Esta dicotomía también se pone de manifiesto en los estereotipos femeninos representado en publicidad, donde queda perfectamente diferenciados dos estereotipos principales (que se pueden subdividir a su vez en diferentes grupos) el de ama de casa y el de mujer objeto de deseo, el primero relacionado con lo que se debe hacer, representado en un ámbito privado, mientras que el segundo se muestra erotizado y vinculado a un ámbito público. Las imágenes femeninas publicadas previamente han sido manipuladas por programas de retoque fotográfico, principalmente por Adobe Photoshop, presentando un diferente canon de belleza dependiendo si la mujer se encuentra ubicada en un ámbito privado o en uno público, usándose retoques digitales diferentes.

\section{Referencias bibliográficas}

ALANDETE, David (2011): "Contra la eterna juventud del Photoshop". [elpais.com. Consulta: 20/09/2013] http://sociedad.elpais.com/sociedad/2011/12/11/vidayartes/1323629771_756737.html

AROCENA, Carmen y ZUBIAUR, Nekame (2012): "En el limbo de lo invisible". Fotocinema: revista cientifica de cine y fotografia, (4), pp. 10-36.

FELIU, Ángeles y FERNÁNDEZ, Ma Dolores (2010): "La mujer en la publicidad: hacia nuevos discursos". En: La representació de gènere a la publicitat del segle XXI. [Consulta: 9/09/2013]: http://www3. udg. edu/publicacions/vell/electroniques/congénere

AUMENTE, María del Pilar (2010): "La imagen de las mujeres a través de su propia mirada". Creatividad y sociedad: revista de la Asociación para la Creatividad, (15), pp. 3-28. 
BEALL, Jade (2013): “A Beautiful Body. Book Project”. [Consulta: 9/09/2013]: http://www.kickstarter.com/projects/1373438121/a-beautiful-body-book-project.

BERNAD, Estela (2010): "Ilicitud de las representaciones degradantes y humillantes del cuerpo femenino en la publicidad. Especial referencia a la anorexia". Icono14, 8 (3), pp. 186-207.

BONNIOL, Jean Luc (1995): "Beauté et couleur de la peau". Communications, 60 (1), pp. 185-204.

BORNAY, Erika (2009): Arte se escribe con M de mujer. Barcelona, sdedicions.

BORNAY, Erika (1994): La cabellera femenina. Un diálogo entre poesía y pintura. Madrid, Cátedra.

BORNAY, Erika (1990): Las hijas de Lilith. Madrid, Cátedra.

BORNAY, Erika (1998): Mujeres de la Biblia en la pintura del Barroco: imágenes de la ambigüedad. Madrid, Cátedra.

CABRERA, Yolanda (2010): "El cuerpo femenino en la publicidad. Modelos publicitarios entre la belleza real, la esbeltez o la anorexia". Icono 14, 8 (3), pp. 223-243.

CÁCERES, María Dolores y DÍAZ SOLOAGA, Paloma (2008): "La representación del cuerpo de la mujer en la publicidad de revistas femeninas". Estudios sobre el Mensaje Periodístico, vol. 14, pp. 309-327. Madrid, servicio de Publicaciones de la Universidad Complutense.

CARRILLO-DURÁN, Ma Victoria (2003): "La transmisión de valores sociales por medio de las imágenes. La identificación de la mujer delgada igual a mujer triunfadora en la población adolescente". Comunicación y sociedad: Revista de la Facultad de Comunicación, 16 (2), pp. 33-47.

CASTAÑAR, Esquí (1993): La imagen de la mujer en la plástica vasca contemporánea (s. XVIII-XX), aproximación a una metodología de género. Bilbao, Universidad País Vasco.

CLAY, Daniel; VIGNOLA'S, Vivian L.; \& DITTMAR, Helga (2005): “Body Image and Self Esteem Among Adolescent Girls: Testing the Influence of Sociocultural Factors". Journal of research on adolescence, 15 (4), pp. 451-477.

CROUCH, Alanda \& DEGELMAN, Douglas (1998): "Influence of female body images in printed advertising on self-ratings of physical attractiveness by adolescent girls". Perceptual and motor skills, 87 (2), pp. 585-586.

DÍAZ SOLOAGA, Paloma y MUÑIZ, Carlos (2007): "Valores y estereotipos femeninos creados en la publicidad gráfica de las marcas de moda de lujo en España". Zer-Revista de Estudios de Comunicación, 12 (23), pp. 75-94.

DIEGO, Estrella de (1992): El andrógino sexuado. Eternos ideales, nuevas estrategias de género. Madrid, Visor.

DIEGO, Estrella de (1987): La mujer y la pintura del XIX español: (cuatrocientas olvidadas y algunas más). Madrid, Cátedra. 
DITTMAR, Helga \& HOWARD, Sarah (2004): “Thin-ideal internalization and social comparison tendency as moderators of media models' impact on women's body-focused anxiety". Journal of Social and Clinical Psychology, 23 (6), pp. 768791.

FAJULA, Anna F.; SOUTO, Ana Belén; y BARBEITO, Ma Luz (2010): "Publicidad y género. Los estereotipos de la mujer en la publicidad radiofónica del 'prime time' generalista". En La representació de gènere a la publicitat del segle XXI. [Consulta: 09/09/2013]: http://www3. udg. edu/publicacions/vell/electroniques/congénere

GARCÍA, Patricia (2003): Estereotipos de género en publicidad televisiva (Tesis doctoral). Málaga, Universidad de Málaga, España.

GARRIDO, Manuel (2007): "Estereotipos de género en publicidad: La creatividad en la encrucijada sociológica". Creatividad y sociedad, (11), pp. 53-71. [Consulta: 09/09/2013]: http://www.creatividadysociedad.com/numeros/cys11.html

GARRIDO, María (2010): "De la Prensa femenina a los periódicos. De la cosmética a la cosmética masculina. Primeros ellas. Ahora ellos y ellas". Icono14, 8 (3), pp. 118-142.

HALLIWELL, Emma \& DITTMAR, Helga (2004): "Does Size Matter? The Impact of Model's Body Size on Women's Body-Focused Anxiety and Advertising Effectiveness". Journal of Social and Clinical Psychology, 23 (1), pp. 104-122.

HEREDIA, Nicolás \& ESPEJO, Gladys (2009): "Historia de la belleza". Historia, 37 (1), pp. 31-46.

IRAZÚ, Yudmila (2006): "Las chicas totalmente palacio o cómo romper para no romper". Espacios Públicos, 9 (18), pp. 233-240.

JONES, Meredith (2013): "Media Bodies and Photoshop". In ATTWOOD, Feona et al. (Eds.): Controversial images: Media representations on the edge. Houndmills, Basingstoke, Hampshire; New York, Palgrave Macmillan, pp. 19-35.

LÓPEZ, Susana (2009): "Publicidad e identidades: cuando la publicidad favorece la igualdad de género". En: La representació de gènere a la publicitat del segle XXI. [Consulta: 09/09/2013]: http://www3. udg. edu/publicacions/vell /electroniques/congénere

LEÓN, José Luis (1996): Los efectos de la publicidad. Barcelona, Ariel.

LEÓN, José Luis (1998): "Mitoanálisis e ideología de la publicidad". Comunicación \& cultura, (3), pp. 65-78.

MALUENDA, Tanya C. (2010): Pornokitsch. El cuerpo femenino como fetiche. (Tesis Doctoral). Granada, Universidad de Granada, España.

MARTÍNEZ, Estrella (2010): "Los ojos femeninos en la publicidad audiovisual". Icono14, 8 (3), pp. 257-266.

MARTÍNEZ, Remedios (2007): "Mujeres y medios de comunicación". Comunicación e xénero: actas do Foro Internacional, celebrado en Liña, Pontevedra, 9-oc- 
tubre-25 noviembre de 2006, pp. 37-44. Colexio Profesional de Xornalistas de Galicia.

MOYA, Isabel (2010): El sexo de los ángeles. Una mirada de género a los medios de comunicación. La Habana, Centro Félix Varela, Ediciones Acuario.

ORTIZ, Julieta (1998): “Arte, publicidad y consumo en la prensa. Del porfirismo a la posrevolución”. Historia Mexicana, XLIII (2), pp. 411-435.

ORTIZ, Julieta (2003): Imágenes del deseo. Arte y publicidad en la prensa ilustrada mexicana 1894-1939. México, D. F., UNAM, Dirección General de Estudios de Posgrado.

PEÑA-MARIN, Cristina y FRABETTI, Carlo (1990): La mujer en la publicidad. Madrid, Instituto de la Mujer.

PÉREZ, M José y ROMERO CALMACHE, María (2010): "El mercado mediático de la belleza: estudio de la estructura de ingresos en revistas femeninas de alta gama". Icono 14, 8 (3), pp. 9-25.

PRÜSSING, Cheryl y SALAZAR, Constanza (2009): Belleza y publicidad. (Tesis para obtener el título de periodista). Universidad de ARCIS, Santiago de Chile. [Consulta: 15/11/2013]: ftp://200.54.148.78/PE/bellezapublicidad.pdf

RAMÍREZ, Gonzalo; CUADRA, Joaquín de la; RIES, Francis; y RODRÍGUEZ, Augusto R. (2011): "Estereotipos y roles sociales de la mujer en el cine de género deportivo". Teoría de la Educación. Educación y Cultura en la Sociedad de la Información, 12 (2), pp. 82-104.

RAMOS, Eva María (2009): “Imágenes seductoras en la publicidad de las revistas ilustradas". Congreso Internacional Imagen Apariencia. Noviembre 19, 2008 - noviembre 21, 2008, p. 33. Murcia, Universidad de Murcia, Servicio de Publicaciones.

RODRÍGUEZ, Nuria (2012): Las mujeres y un pintor. La imagen de la femme fatale y la mujer española de principios de siglo XX. (Trabajo Fin de Máster). Instituto de Investigaciones Feministas. Universidad Complutense de Madrid.

SABELLI, Sonia (2012): "La herencia del colonialismo en las representaciones contemporáneas del cuerpo negro femenino". Revista Sans Soleil-Estudios de la imagen, 4 (1), pp. 122-131.

SAIZ, Jesús; FERNÁNDEZ RUIZ, Beatriz; y ÁLVARO ESTRAMIANA, José Luis (2007): "De Moscovici a Jung: el arquetipo femenino y su iconografía". Athenea digital, (11), pp. 132-148.

SAURET, Teresa (2007): "La estética del silencio: iconografía femenina de la época isabelina". Boletín de Arte, (28), pp. 127-151.

SOLEY, Patricia (2012): "Muñecas que hablan. Ética y estética de los modelos de belleza en publicidad y moda". Revista de dialectología y tradiciones populares, 67 (1), pp. 115-146. 
ULIERTE, Luz de (1997): "Sirenas: del mito a la publicidad". En: La Mujer en el arte Español: [actas de las] VIII Jornadas de Arte [Departamento de Historia del Arte "Diego Velázquez", Centro de Estudios Históricos, CSIC, Madrid, 26-29 de noviembre de 1996], pp. 559-570. Madrid, Alpuerto.

ULIERTE, Luz de (1998): "Imágenes de la mujer: de Gea a María". Cuadernos de Arte, (29), pp. 83-200.

VELÁSQUEZ, Kasbrika (2013): Representación de la estética en la mujer venezolana, a través de las revistas Urbe Bikini y Playboy Venezuela (Tesis doctoral). Universidad Central de Venezuela.

VERCHILI, Elena (2012): "De las casa de las Muñecas al Gloss. La irrupción de la industria de la belleza en la cultura mediática infantil". Icono 14. Revista científica de Comunicación y Tecnologías emergentes, 8 (3), pp. 26-44.

VILLARREAL, Ana Lucia (2010): "Publicidad Televisiva. Reproduce cautiverios femeninos". Escena, 33 (66), pp. 137-154. 